\title{
Multi-Attribute Group-Decision on a Construction Diversion Scheme for Hydropower Projects Based on Perception Utility
}

\author{
Dawei Liu ${ }^{1}$, Zhigen $\mathrm{Hu}^{1, *}$ and Wencheng Guo ${ }^{2, *}$ \\ 1 State Key Laboratory of Water Resources and Hydropower Engineering Science, Wuhan University, \\ Wuhan 430072, China; dawei.liu@whu.edu.cn \\ 2 School of Hydropower and Information Engineering, Huazhong University of Science and Technology, \\ Wuhan 430074, China \\ * Correspondence: zhigenhu@whu.edu.cn (Z.H.); wencheng@hust.edu.cn (W.G.); \\ Tel.: +86-136-0719-2629 (Z.H.); +86-159-2620-2836 (W.G.)
}

Received: 10 October 2018; Accepted: 1 November 2018; Published: 4 November 2018

\begin{abstract}
The multi-attribute and group-decision problem in the selection of a construction diversion scheme for large hydropower projects often involves multi-decision subjects and schemes. Each scheme includes multiple attributes, and the attribute values and weights are multi-attribute group decision-making problems with interval numbers. In this study, a new method for solving the multi-attribute group-decision problem is proposed by integrating regret theory, negotiation gathering theory, and the Monte Carlo simulation technique. Firstly, decision-makers' comprehensive perception utility for each scheme is calculated based on the regret theory. Then, non-uniform and fuzzy opinion of different decision subjects are negotiated and gathered, and negotiation intervals of the attribute weights are calculated through group negotiation gathering theory. Moreover, fuzzy complementary judgment matrixes describing an excellent degree of the diversion schemes are obtained by conducting Monte Carlo simulations. Finally, the alternative diversion schemes are sorted in terms of their priorities, and the reliability of the sorting procedure is confirmed. The multi-attribute group-decision problem in the selection of a construction diversion scheme for Jinping I Hydropower Station is effectively solved by the proposed method. The proposed method is reliable and may significantly contribute to engineering decision-making.
\end{abstract}

Keywords: construction diversion; multiple attributes; group decision; perception utility; regret theory; Monte Carlo

\section{Introduction}

River diversion during dam construction is a way to provide a safe and free-of-water working area so that the permanent works may be built in the dry. The construction may include full or partial encircling of the working area with a low dam that diverts water away from the working area into a temporary waterway, such as a tunnel. Whether the diversion works is well planned or not will directly influence the effect of construction and economy of dam construction; therefore, a reasonable selection of the diversion scheme is of great practical engineering significance [1]. Large hydropower project requires consideration of many factors such as investment cost, construction period, failure risk, and inundation loss. Furthermore, the decision-makers involve many groups of interest such as owner, design, and construction organizations. Thus, the selection of a diversion scheme is a complicated multi-attribute group decision-making problem that requires both a comprehensive assessment of multiple factors and a consideration of multiple decision-makers. In addition, attribute values and their weight values in each scheme cannot be easily given in a deterministic manner because of system 
complexity and many uncertain factors [2]. Therefore, a method for solving the multi-attribute group decision-making problem in the selection of a diversion scheme for hydropower projects is essential to dam construction.

During the process of decision-making about the multi-attribute in construction diversion schemes, Zhong et al. [3] proposed the selective distribution based on the Genetic Algorithm and Analytic Hierarchy Process for the problem with nonlinear multi-objective optimization. With several factors after comprehensive consideration in construction diversion-making, Men et al. [4] set up a model called multi-criteria decision gray relation projection. Based on Monte Carlo, Afshar et al. [5] established multi-criteria decision of construction diversion. These scholars all assumed that the conduct of those decision-makers was rational, and they did not consider the entirety and incompatibility according to their preferences among those interest-related groups.

Therefore, based on analyzing the difference in value orientation from those groups and considering the multi-decision-making in construction diversion from those groups, scholars like Xue et al. [6] focused on comparatively satisfying the decision-makers and coordinating the interest demand of contradictory sides on the basis of the consulted countermeasure. However, he did not consider diversion made by decision-makers in evaluation utility and uncertainty to the information of decision-making. Meanwhile, the difficulty in the research of group decision-making is making sure the evaluation utility of experts in making decisions deal with the illegibility from the information and realize the concentration on the decision-makers' preferences. To the problem that is an interval number as a result of the decision-making information, as well as the completely unknown attribute weight, Qi et al. [7] proposed a decision-making method based on the information-entropy, which can ensure the form of an interval number and can decrease the loss of information as soon as possible. To avoid the risky problem of decision-making by groups caused by the random variable from attribute value and its weight, with the help of Bayes Theory and Monte Carlo, Bi et al. [8] brought forward two Bayes Models in probability distribution concluded from decision-makers and experts.

Considering the rational conduct of those decision-makers, the forward theory and its value function and weight function have been studied [9-13] and have been widely used in many fields [14,15]. In contrast, the regret theory proposed by Bell [16] as well as Loomes and Sugden [17] in 1982 is more advantageous.

The regret theory considers the mentality of the deciders. Scholars such as Larrick, Ritov, Zeelenberg, and Corielli [18-21] have verified the mental characteristics of regret aversion in the human decision-making process by applying psychology and neuro-imaging techniques. The decision model using the regret theory is simpler than that using the prospect theory [22]: it has only one additional parameter (i.e., regret-averse coefficient), it does not require the reference information, and the regret theory can solve the problems that are not solvable by the EU theory and the prospect theory [23]. It is recognized that the regret theory provides more reliable decision-making results than the EU theory and the prospect theory [24].

Since the decision-making on a diversion scheme can be considered as a multi-attribute group-decision problem involving multiple decision-makers and attributes, this study proposes that the problem can be effectively solved by using the regret theory. Note that the attribute values and weights in each scheme are interval numbers. First, the utility value and regret value of different schemes' attribute values are calculated based on the regret theory. The utility value and regret value are summed to obtain the decision-makers' comprehensive perception utility on each scheme. Then, a diversion scheme group-decision method is proposed based on a probability matrix representation by combining the group negotiation gathering theory. The negotiation intervals of attribute weights can be calculated by negotiating and gathering non-uniform and fuzzy views of different decision-makers in each diversion scheme. Finally, diversion schemes are compared based on their probability of superiority. A fuzzy complementary judgment matrix describing the superiority of a diversion scheme over the other scheme is further obtained based on the Monte Carlo simulation technique, and hence, the scheme with the greatest probability of superiority is selected. 


\section{Multi-Attribute Group-Decision Problem of a Diversion Scheme}

In a decision-making process on a diversion scheme for hydropower projects, the owner $(O)$, design unit $(D)$, and construction unit $(C)$ are the three parties of decision-makers. Specifically, the owner is the investor and immediate beneficiary of the project, whereas the design unit proposes the alternative diversion schemes and the construction unit is responsible for the construction of the diversion scheme.

For convenience, let $M=\{1,2, \ldots, m\}$ and $N=\{1,2, \ldots, n\}$. Then $A$ can be noted as $A=\left\{A_{1}, A_{2}, \ldots\right.$, $\left.A_{m}\right\}$, which represents a set of alternative diversion schemes in which $\mathrm{m}$ is the total number of schemes and $A_{\mathrm{i}}$ means the $i$-th diversion scheme for $i \in M$. At the same time, we select $X=\left\{x_{1}, x_{2}, \ldots, x_{n}\right\}$ to indicate a set of attribute values for each scheme where $x_{j}$ represents the $j$-th attribute for $j \in N$ and is independent of each other. Moreover, $w=\left\{w_{1}, w_{2}, \ldots, w_{n}\right\}$ is a weight vector of attributes in which $w_{j}$ indicates weight or importance of an attribute $x_{j}$, satisfying $w_{j} \geq 0$ and $\sum_{j=1}^{n} w_{j}=1$. The weight interval of an attribute $x_{j}(j=1,2, \ldots, n)$ from the $k$-th decision-maker is denoted as $\bar{\mu}_{k}^{j}=\left[\mu_{k}^{j L}, \mu_{k}^{j U}\right]$ $(k=1,2, \ldots, n)$, which satisfies $\sum_{j=1}^{n} \mu_{k}^{j L} \leq 1, \sum_{j=1}^{n} \mu_{k}^{j U} \geq 1,0 \leq \mu_{k}^{j L} \leq 1$ and $0 \leq \mu_{k}^{j U} \leq 1$. The risk decision-making matrix of the diversion scheme is denoted as $D=\left[\bar{d}_{i j}\right]_{m \times n^{\prime}}$ and $\bar{d}_{i j}$ represents the results for $x_{j}$ under scheme $A_{i} . \bar{d}_{i j}$ is an interval number, and $\bar{d}_{i j}=\left[d_{i j}^{l}, d_{i j}^{u}\right]$. When $d_{i j}^{l} \leq d_{i j}^{u}, i \in M, j \in$ $N$, the risk decision-making matrix $D$ has the form shown in Table 1.

Table 1. Risk decision-making matrix for a diversion scheme.

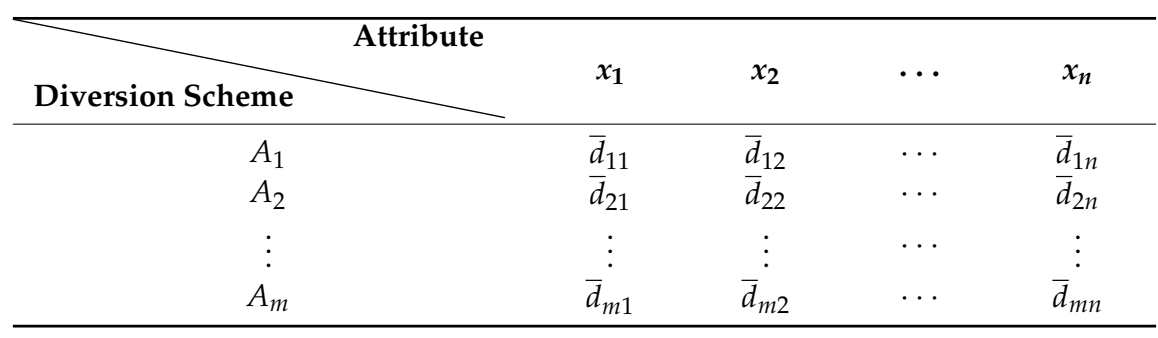

It should be pointed out that the diversion projects are temporary buildings, and the decision-makers need to comprehensively consider many factors when selecting the schemes. On the one hand, they hope to save investment costs, speed up construction process, and put hydropower projects into operation as soon as possible. On the other hand, they hope that the diversion standard will be higher and reduce the losses caused by possible floods. As the purpose of the diversion project is to ensure the dry construction of the major project, the decisive factors mainly include investment cost, construction intensity and risk loss in the multi-attribute decision-making problem of construction diversion in a hydropower project. From the entire construction diversion project, these factors feature the cost-effective attributes. Considering the difference in interest preferences and knowledge structure, the perceptual utility of decision-makers differs among themselves when assessing different attributes. For example, the investment cost is a cost attribute for the investor, but a profit attribute for the construction unit.

When the regret aversion mentality of decision-makers is considered, a reliable scheme can be sorted by an effective decision-making analysis method based on the risk decision-making matrix $D$ and the attribute weight interval vector $\bar{\mu}$.

\section{Multi-Attribute Group-Decision Model for Diversion Scheme Based on Perception Utility}

\subsection{Comprehensive Perception Utility for a Diversion Scheme}

In the multi-attribute group decision-making process of a diversion scheme, decision-makers will compare the results of a selected diversion scheme with those obtained from the alternative schemes. If they find that results of the alternative schemes are better or worse, they will regret or be 
delighted, respectively. Therefore, in the decision-making process, decision-makers will have either an expected regret value or rejoice value when they select different schemes, and they will try to avoid selecting those schemes that lead to regret. According to the regret theory $[16,17]$, the perception utility function of the decision-makers for a diversion scheme is composed of two parts: utility function and regret-rejoice function for a selected scheme. Let $A_{1}, A_{2}, \ldots, A_{m}$ be $m$ alternative diversion schemes in which $A_{i}$ is the $i$-th scheme. $x_{1}, x_{2}, \ldots, x_{m}$ are the results of schemes from $A_{1}, A_{2}, \ldots, A_{m}$. And the decision-makers' perception utility on scheme $A_{i}$ can be given by

$$
u_{i}=v\left(x_{i}\right)+R\left(v\left(x_{i}\right)-v\left(x^{*}\right)\right)
$$

In Equation (1), $v\left(x_{i}\right)$ represents the utility that the decision-makers perceive from scheme $A_{1}, A_{2}$, $\ldots, A_{m} . v\left(x^{*}\right)$ is the maximum utility among the $m$ schemes, in which $x^{*}=\max \left\{x_{i} \mid i=1,2, \ldots, m\right\}$. $R\left(v\left(x_{i}\right)-v\left(x^{*}\right)\right)$ represents regret values. $R\left(v\left(x_{i}\right)-v\left(x^{*}\right)\right) \leq 0$ indicates the degree of regret of decision-makers after selecting scheme $A_{i}$. The regret-rejoice function $R(\cdot)$ is a monotone increasing concave function [25] and meets the requirements that $R^{\prime}(\cdot)>0, R^{\prime \prime}(\cdot)<0$ and $R(0)=0$.

In order to eliminate the influence of the attribute dimension of a diversion scheme on the decision-making result, first, the decision-making matrix $D=\left[\bar{d}_{i j}\right]_{m \times n}$ should be normalized as a non-dimensional decision-making matrix $B=\left[\bar{b}_{i j}\right]_{m \times n}$. In this study, the decision-making matrix $D$ is normalized as follows [26]:

$$
\begin{aligned}
& b_{i j}^{l}=\left(q_{j}-d_{i j}^{u}\right) /\left(q_{j}-g_{j}\right), i \in M, j \in N \\
& b_{i j}^{u}=\left(q_{j}-d_{i j}^{l}\right) /\left(q_{j}-g_{j}\right), i \in M, j \in N
\end{aligned}
$$

where

$$
\begin{aligned}
& g_{j}=\min \left\{d_{i j}^{l} \mid i \in M\right\}, j \in N \\
& q_{j}=\max \left\{d_{i j}^{u} \mid i \in M\right\}, j \in N
\end{aligned}
$$

Secondly, an ideal point $I^{+}=\left(\bar{b}_{1}^{*}, \bar{b}_{2}^{*}, \ldots, \bar{b}_{n}^{*}\right)$ is constructed where $b_{j}^{*}=\left[b_{j}^{l *}, b_{j}^{u *}\right]$. An equation for $b_{j}^{l *}$ and $b_{j}^{u *}$ is as follows:

$$
b_{j}^{l *}=b_{j}^{u *}=\max \left\{b_{i j}^{u} \mid i \in M\right\}, j \in N
$$

Then, the utility value $v_{i j}$ of the attribute value $\bar{b}_{i j}$ is calculated, namely the part where the decision-makers can obtain the utility from $\bar{b}_{i j}$. The utility function $v\left(x_{i}\right)$ should be constructed at first, as the decision-makers are usually risk-averse in the decision-making on the diversion scheme. A monotone increasing power function is taken as the utility function of attribute value $\bar{b}_{i j}$ in this study [27]:

$$
v(x)=x^{\alpha}
$$

In Equation (7), $\alpha$ is the risk-averse coefficient of the decision-makers, $0<\alpha<1$. If $\alpha$ is relatively smaller, the degree of the decision-makers' risk aversion is relatively stronger. Here, $x$ represents an attribute value, and $v(x)$ indicates the utility value of the attribute value.

For the attribute value $\bar{b}_{i j}$, the interval $\left[b_{i j}^{l}, b_{i j}^{u}\right]$ is relatively fixed. Thus, the actual attribute $x$ is valued randomly in the interval $\left[b_{i j}^{l}, b_{i j}^{u}\right]$ and follows a typical statistical distribution [28]. If the probability density function of $x$ is $f_{i j}(x)$, the utility value $v_{i j}$ of the attribute value $\bar{b}_{i j}$ can be expressed as

$$
v_{i j}=\int_{b_{i j}^{l}}^{b_{i j}^{u}} v(x) f_{i j}(x) d x, i \in M, J \in N
$$


By considering that $x$ follows the normal distribution [26], the probability density function of $x$ is

$$
f_{i j}(x)=\frac{1}{\sqrt{2 \pi} \sigma_{i j}} \exp \left[-\left(x-\mu_{i j}\right)^{2} / 2\left(\sigma_{i j}\right)\right]
$$

where $i \in M, j \in N, \mu_{i j}=\left(b_{i j}^{l}+b_{i j}^{U}\right) / 2$, and $\sigma_{i j}=\left(b_{i j}^{l}-b_{i j}^{U}\right) / 6$.

In this study, $R(\Delta v)=1-\exp (-\delta \Delta v)$ is adopted to represent the regret-rejoice function [17,24] where parameter $\delta \in[0,+\infty]$ is the regret-averse coefficient of the decision-makers. A relatively larger value of $\delta$ means a relatively larger degree of the regret aversion by the decision-makers, and vice versa.

Therefore, the regret-rejoice value of scheme $A_{i}$ given $x_{j}$ relative to the ideal point can be obtained as

$$
R_{i j}=1-\exp \left[-\delta\left(v_{i j}-v_{j}^{*}\right)\right], i \in M, j \in N
$$

In Equation (10),

$$
v_{j}^{*}=\int_{b_{i j}^{l *}}^{b_{i j}^{u *}} v(x) f_{j}^{*}(x) d x=\left(b_{j}^{u *}\right)^{\alpha}, i \in M, J \in N
$$

Based on Equations (10) and (11), a regret value matrix $R=\left[R_{i j}\right]_{m \times n}$ can be established. Furthermore, a perception utility matrix $U=\left[u_{i j}\right]_{m \times n}$ of the decider can be established according to Equation (1). Here, $u_{i j}$ represents the decision-makers' perception utility on scheme $A_{i}$ given $x_{j}$ and can be calculated as

$$
u_{i j}=v_{i j}+R_{i j}, i \in M, J \in N
$$

Based on Equation (12), the comprehensive perception utility of the decision-makers, on scheme $A_{i}$ can be obtained as

$$
U_{i}=\sum_{j=1}^{n} w_{j} u_{i j}, i \in M
$$

\subsection{An Attribute Weight Negotiation Interval Based on the Negotiation Gathering Theory}

In the decision-making process of a diversion scheme, the evaluation impact (the impact on evaluation results) of different decision-makers is unequal [29]. Even if the same decision-maker evaluates different attributes, the corresponding evaluation impacts are different. Following the study of Madlener et al. [30], the decision-making group's judgement on the evaluation impact of a decision-maker is most convincing. In other words, the evaluation impact of a decision-maker depends on the degree of recognition of other decision-makers in the group.

Besides, since different decision-makers assign different weights for the same attribute, the weights from all the decision-makers should be negotiated and integrated into group weights, and a weight negotiation interval for a particular attribute can be obtained accordingly. To obtain the negotiation intervals for different attributes, an objective function is constructed to minimize the total difference between the negotiation interval and all the decision-makers' intervals.

Let $\eta_{p q}^{j}(p, q=1,2,3)$ denote the score of evaluation impact that the $p$-th decision-maker give to the $q$-th decision-maker for attribute $c_{j}$, satisfying $0<\eta_{p q}^{j}<1, \eta_{p q}^{j}=0$ and $\sum_{q=1}^{3} \eta_{p q}^{j}=1$. Therefore, $\eta_{p q}^{j}$ are the elements of the mutual-evaluation matrix $\eta_{j}=\left(\eta_{p q}^{j}\right)_{3 \times 3}$ of evaluation impact for attribute $x_{j}$. Let $\pi^{j}=\left\{\pi_{1}^{j}, \pi_{2}^{j}, \pi_{3}^{j}\right\}$ in which $\pi_{k}^{l}$ is the evaluation impact of the $k$-th decision-maker for attribute $x_{j}$ The evaluation impact of a decision-maker is equal to the weighted average of other decision-makers' scores, i.e., $\pi^{j}=\pi^{j} \times \eta_{j}$.

Since $\eta_{j}$ is a transition probability matrix, there is one unique solution for the equation $\pi^{j}=\pi^{j}$ $\times \eta_{j}$ given $0<\pi_{k}^{j}<1$ and $\sum \pi_{k}^{j}=1$ according to the reducibility of Markov chain. As a result, the evaluation impact matrix $\pi$ of the various decision-makers for the different attributes can be obtained as 


$$
\pi=\left(\pi_{k}^{l}\right)_{m \times 3}=\left(\begin{array}{ccc}
\pi_{1}^{1} & \pi_{2}^{1} & \pi_{3}^{1} \\
\pi_{1}^{2} & \pi_{2}^{2} & \pi_{3}^{2} \\
\vdots & \vdots & \vdots \\
\pi_{1}^{m} & \pi_{2}^{m} & \pi_{3}^{m}
\end{array}\right)
$$

Setting the weight negotiation interval of attribute $x_{j}$ to be $\bar{w}_{j}=\left[w^{j L}, w^{j U}\right],\left[\varepsilon^{j L}, \varepsilon^{j U}\right] .(j \in N)$ represents the total difference between the negotiation interval and all the decision-makers' intervals for attribute $x_{j}$. Then, the solution programming model for the weight negotiation interval is given by

$$
\begin{gathered}
\min ^{j L}=\sum_{k=1}^{3} \pi_{k}^{j}\left(w^{j L}-\mu_{k}^{j L}\right)^{2} \\
\text { s.t.min }\left[\mu_{k}^{j L}\right] \leq w^{j L} \leq \max _{k}\left[\mu_{k}^{j L}\right] \\
\min ^{j U}=\sum_{k=1}^{3} \pi_{k}^{j}\left(w^{j U}-\mu_{k}^{j U}\right)^{2} \\
\text { s.t.min } \left.\min _{k}^{j u}\right] \leq w^{j U} \leq \max _{k}\left[\mu_{k}^{j U}\right]
\end{gathered}
$$

Based on Equations (15) and (16), the weight negotiation intervals for the various attributes are given as $\bar{w}_{j}=\left[w_{j}^{L}, w_{j}^{U}\right](j \in N)$.

\subsection{Ranking of Diversion Schemes Using Monte Carlo Simulation}

Monte Carlo simulation is a numerical method to achieve a convergent estimation of system response through a large number of simulations. In each simulation, a random sample is generated from the probability distribution of the random variables investigated, and the system response is calculated by substituting the sample into the system. As the number of simulation becomes relatively large, the convergent probability distribution of system response can be obtained. In this study, the attribute weight in a diversion scheme is an interval number. Therefore, the attribute weight can be considered as a random variable bounded on the given interval [31].

Assume that $w_{j}^{*}$ is a random variable bound on the interval $\left[w_{j}^{L}, w_{j}^{U}\right]$ and is uniformly distributed. Then $W^{*}=\left(w_{1}^{*}, w_{2}^{*}, \ldots, w_{n}^{*}\right)$ is a weight random vector for $n$ attributes.

For two diversion schemes, $A_{i 1}$ and $A_{i 2}, s\left(A_{i 1}>A_{i 2}\right)$ is used to indicate the probability that $A_{i 1}$ is superior to $A_{i 2}$, so:

$$
s\left(A_{i 1}>A_{i 2}\right)=P\left(f\left(A_{i 1}\right)>f\left(A_{i 2}\right)\right)+0.5 P\left(f\left(A_{i 1}\right)=f\left(A_{i 2}\right)\right)
$$

where

$$
f\left(A_{i}\right)=\sum_{j=1}^{n} w_{j}^{*} u_{i j}, i \in M
$$

With the aid of Monte Carlo simulation, the probability matrix $S$ describing the superiority of a diversion scheme against another diversion scheme can be obtained as

$$
S=\left(\begin{array}{cccc}
s_{11} & s_{12} & \cdots & s_{1 m} \\
s_{21} & s_{22} & \cdots & s_{2 m} \\
\vdots & \vdots & \cdots & \vdots \\
s_{m 1} & s_{m 2} & \cdots & s_{m m}
\end{array}\right)
$$

In Equation (19), $s_{i i^{\prime}}=s\left(A_{i}>A_{i^{\prime}}\right)$, and it shows the scheme probability that $A_{i}$ is superior to $A_{i^{\prime}}$.

Let $h_{i}(i=1,2, \ldots, m)$ denote the integrated probability that diversion scheme $A_{i}$ is superior to the remaining diversion schemes in set $A$ of alternative diversion schemes. Then $h_{i}$ can be expressed as 


$$
h_{i}=\frac{1}{n-1}\left(\sum_{i^{\prime}=1}^{m} s_{i i^{\prime}}-0.5\right), i \in m
$$

If $h_{i}$ is equal to 1 , scheme $A_{i}$ is absolutely superior to the remaining schemes, and it should be assigned the first rank. On the other hand, if $h_{i}$ is equal to 0 , scheme $A_{i}$ should be assigned the last rank. Therefore, ranking of diversion schemes can be conducted according to the value of $h_{i}$ [32].

To characterize the reliability of the ranking results, a ranking reliability coefficient $\tau$ is introduced. Assuming the ranking result of the schemes is $A_{1}{ }^{\prime}>A_{2}{ }^{\prime}>\ldots>A_{n}{ }^{\prime}$, the ranking reliability coefficient is given by

$$
\tau\left(A_{1}{ }^{\prime}>A_{2}{ }^{\prime}>\ldots>A_{n}{ }^{\prime}\right)=\sqrt[n-1]{\prod_{i=1}^{n-1} \rho_{i}}
$$

In Equation (21), $\rho_{i}$ is the averaged probability of superiority of scheme $A_{i}{ }^{\prime}$ to the subsequent schemes. The expression for $\rho_{i}$ is as follows:

$$
\rho_{i}=\sum_{k=i+1}^{n} s\left(A_{i}>A_{k}\right) /(n-i)
$$

In summary, the flowchart describing the main steps of multi-attribute group-decision on a diversion scheme based on the regret theory is shown in Figure 1.

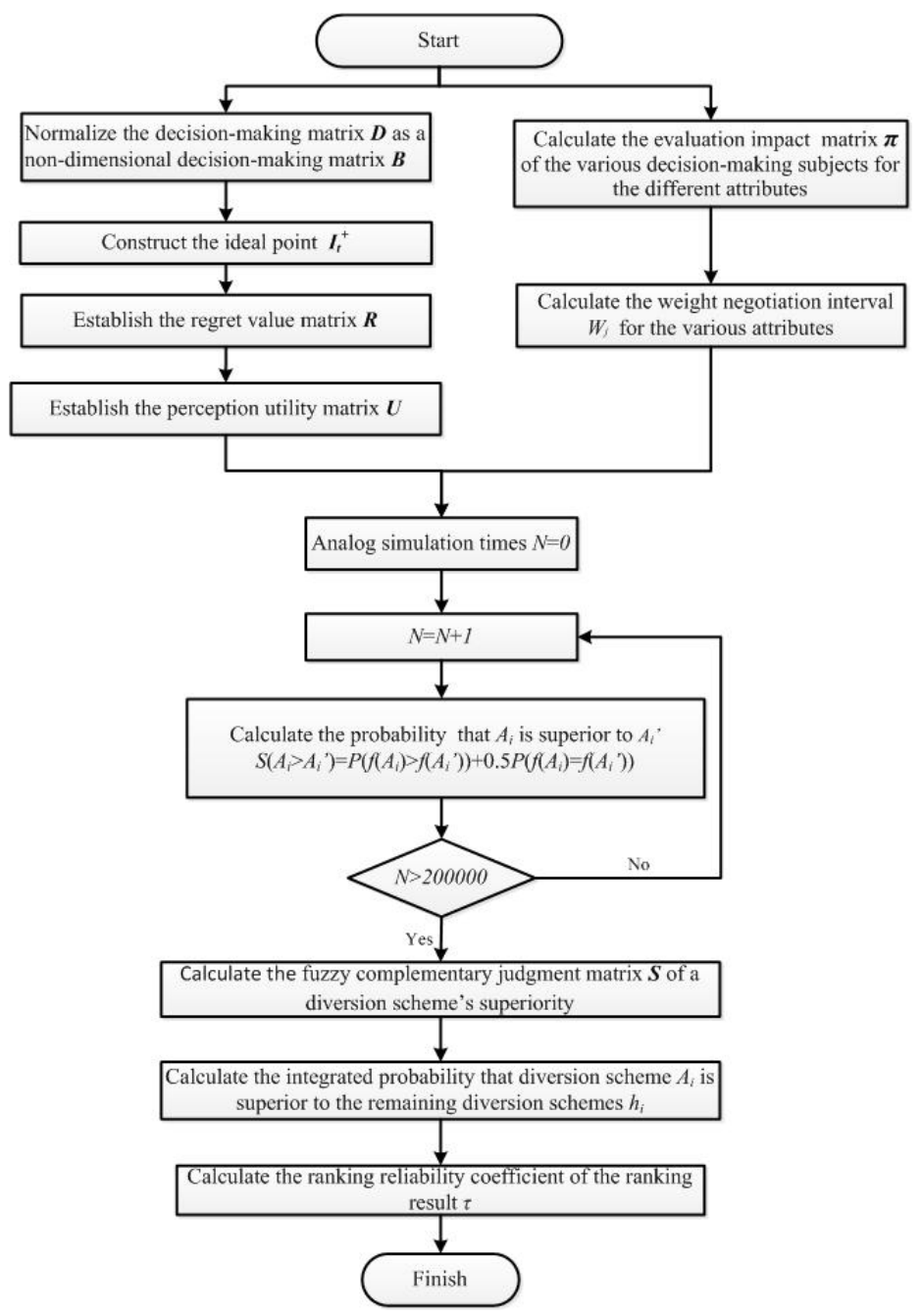

Figure 1. Flowchart of multi-attribute group decision-making on a diversion scheme. 


\section{Engineering Application}

Jinping I Hydropower Station Dam, the highest arch dam in the world, is a double-curvature arch dam with a height of $305 \mathrm{~m}$ and the height of excavated slopes at abutments is over $500 \mathrm{~m}$. The construction process is shown in Figure 2. The hydropower station is located in high mountains and narrow canyons in Southwest China. The total installed capacity is $3300 \mathrm{MW}$. The reservoir's normal water level is $1880 \mathrm{~m}$. The total storage capacity is 7.76 billion $\mathrm{m}^{3}$, and the regulating storage is 4.91 billion $\mathrm{m}^{3}$. The total construction period is nine years and three months, and the total investment was 23.23 billion RMB. According to Hydropower Junction Project Hierarchy and the Design Safety Standards, the pivotal project is ranked in the 1st grade, and the main structures are also ranked in the 1st grade. Considering the topographical and geological conditions and the flooding characteristics, earth-rock no-overflow-cofferdam was used for retaining water, and the diversion scheme was a tunnel diversion. Six alternative diversion schemes were considered initially, with the essential attributes as shown in Table 2.

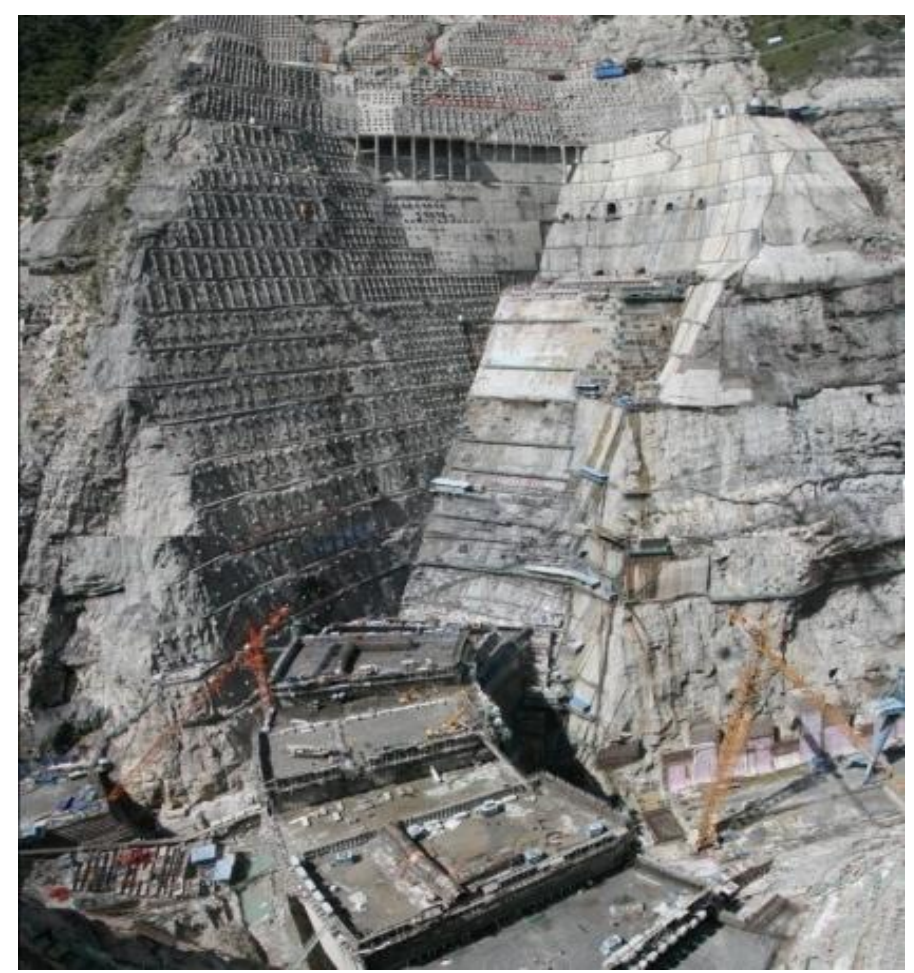

Figure 2. Construction of Jinping I hydropower station.

Table 2. Parameters of the six alternative diversion schemes for Jinping I hydropower station.

\begin{tabular}{|c|c|c|c|c|c|}
\hline \multicolumn{3}{|c|}{ Scheme Description } & \multirow{2}{*}{$\begin{array}{c}\text { Investment } \\
\text { Cost } \\
\left(10^{4} \mathrm{RMB}\right)\end{array}$} & \multirow{2}{*}{$\begin{array}{l}\text { Construction } \\
\text { Intensity } \\
\left(10^{4} \mathrm{~m}^{3} / \text { month }\right)\end{array}$} & \multirow{2}{*}{$\begin{array}{l}\text { Risk Damage } \\
\left(10^{4} \text { RMB }\right)\end{array}$} \\
\hline Scheme & $\begin{array}{l}\text { Flood Return Period } \\
\text { (Year) }\end{array}$ & $\begin{array}{l}\text { Diversion Tunnel Size } \\
\quad(\mathrm{m} \times \mathrm{m})\end{array}$ & & & \\
\hline$A_{1}$ & 20 & $15 \times 18$ & {$[32,526,39,754]$} & {$[13.9,16.9]$} & {$[2698,3298]$} \\
\hline$A_{2}$ & 30 & $15 \times 18$ & {$[33,462,40,898]$} & {$[17.1,20.9]$} & {$[1832,2239]$} \\
\hline$A_{3}$ & 50 & $15 \times 18$ & {$[34,695,42,405]$} & {$[21.5,26.3]$} & {$[1114,1362]$} \\
\hline$A_{4}$ & 20 & $16 \times 20$ & {$[33,327,40,733]$} & {$[8.8,10.8]$} & {$[2538,3102]$} \\
\hline$A_{5}$ & 30 & $16 \times 20$ & {$[33,858,41,382]$} & {$[10.5,12.9]$} & {$[1557,1903]$} \\
\hline$A_{6}$ & 50 & $16 \times 20$ & {$[34,623,42,317]$} & {$[13.1,16.1]$} & {$[987,1207]$} \\
\hline
\end{tabular}

Since the owner, design organization, and construction organization have different preferences on the same attribute, they give different intervals for the attribute weight. The intervals of the attribute weights as estimated by the three decision-makers are shown in Table 3. 
Table 3. Interval estimation of the attribute weights by the three decision-makers.

\begin{tabular}{cccc}
\hline Decision-Maker & Investment Cost & Construction Intensity & Risk Damage \\
\hline Owner & {$[0.400,0.500]$} & {$[0.200,0.250]$} & {$[0.300,0.400]$} \\
Design organization & {$[0.450,0.550]$} & {$[0.300,0.400]$} & {$[0.200,0.250]$} \\
Construction organization & {$[0.350,0.450]$} & {$[0.100,0.150]$} & {$[0.450,0.550]$} \\
\hline
\end{tabular}

The calculation process for the alternative diversion schemes comparison is as follows:

(1) Normalized decision-making matrix was established based on Equations (2)-(6), and the comprehensive perception utility matrix of the decision-makers on the schemes was established according to Equations (7)-(13), where $\alpha=0.88$ and $\delta=0.3$ following the study of Barberis et al. [11]. The calculation results are shown in Table 4.

Table 4. Decision-makers' comprehensive perception utility matrix.

\begin{tabular}{cccc}
\hline Alternative Scheme & Investment Cost & Construction Intensity & Risk Damage \\
\hline$A_{1}$ & 0.5615 & 0.5505 & -0.1206 \\
$A_{2}$ & 0.4292 & 0.2876 & 0.4537 \\
$A_{3}$ & 0.2476 & -0.1089 & 0.8714 \\
$A_{4}$ & 0.4485 & 0.9328 & -0.041 \\
$A_{5}$ & 0.3719 & 0.8061 & 0.6176 \\
$A_{6}$ & 0.2584 & 0.6069 & 0.9421 \\
\hline
\end{tabular}

It should be noted that, in Table 4, the negative value represents the regret value (negative number) that made by decision-makers to the attribute value may be greater than the utility value if the scheme is selected. The schemes with negative values are generally sorted backwards.

(2) For the investment cost, the owner, design organization, and construction organization give scores of the evaluation impact to each other by considering the knowledge background of the three organizations and the consistency of their opinions. The mutual evaluation results are shown in Table 5.

Table 5. The results of mutual evaluation on investment costs.

\begin{tabular}{cccc}
\hline Investment Cost & Owner & Design Organization & Construction Organization \\
\hline Owner & 0 & 0.75 & 0.25 \\
Design organization & 0.65 & 0 & 0.35 \\
Construction organization & 0.55 & 0.45 & 0 \\
\hline
\end{tabular}

Consequently, the matrix $\eta_{1}$ was obtained as

$$
\eta_{1}=\left(\begin{array}{lll}
0.00 & 0.75 & 0.25 \\
0.65 & 0.00 & 0.35 \\
0.55 & 0.45 & 0.00
\end{array}\right)
$$

Then, through solving the linear homogeneous equation $\pi^{1}=\pi^{1} \times \eta_{1}$, the evaluation impact vector $\pi^{1}$ of the three decision-makers for the investment cost can be obtained as

$$
\pi^{1}=\left(\pi^{1}, \pi^{2}, \pi^{3}\right)=(0.3415,0.3496,0.3089)
$$

Similarly, the evaluation impact vectors of the three decision-makers for the construction intensity and risk damage can also be obtained. The three evaluations impact vectors for the investment cost, construction intensity, and risk damage are summarized in Table 6. 
Table 6. Evaluation impact of the three decision-makers.

\begin{tabular}{cccc}
\hline Decision-Maker & Investment Cost & Construction Intensity & Risk Damage \\
\hline Owner & 0.3145 & 0.4001 & 0.3471 \\
Design organization & 0.3496 & 0.4001 & 0.2207 \\
Construction organization & 0.3089 & 0.1998 & 0.4322 \\
\hline
\end{tabular}

By substituting the results in Table 6 into Equations (15) and (16), the weight negotiation intervals for the three attributes were calculated as shown in Table 7.

Table 7. The weight negotiation intervals for the three attributes.

\begin{tabular}{cccc}
\hline Weight and Attributes & Investment Cost & Construction Intensity & Risk Damage \\
\hline Weight negotiation interval & {$[0.408,0.508]$} & {$[0.220,0.290]$} & {$[0.332,0.432]$} \\
\hline
\end{tabular}

(3) Matlab was used for pairwise comparison of the six alternative diversion schemes by using Equations (17) and (18). The probability matrix $S$ describing the superiority of a diversion scheme against another diversion scheme was calculated by the Monte Carlo simulation based on the following steps:

Step 1: The total number of simulations as $E=200,000 . N=1, F=0$, and diversion scheme indicators $i$ and $j$ are 1:6.

Step 2: A sample of three-dimensional weight vector $W^{*}=\left(w_{1}^{*}, w_{2}^{*}, w_{3}^{*}\right)$ was generated in the three weight negotiation intervals [0.408, 0.508], [0.220,0.290], and [0.332, 0.432] by using a random number generator.

Step 3: $f\left(A_{i}\right)$ and $f\left(A_{i^{\prime}}\right)$ were calculated using the random weight vector $W^{*}$. If $f\left(A_{i}\right)>f\left(A_{i^{\prime}}\right)$, then $F=F+1$; if $f\left(A_{i}\right)=f\left(A_{i^{\prime}}\right), F=F+0.5$; if $f\left(A_{i}\right)<f\left(A_{i^{\prime}}\right), F=F$.

Step 4: $N=N+1$; if $N>E$, go to Step 5; otherwise, go back to Step 2.

Step 5: The probability that scheme $A_{i}$ is superior to scheme $A_{i^{\prime}}$ was obtained as $s\left(A_{i}>A_{i^{\prime}}\right)=$ $F / E$. The result was saved as $s_{i i^{\prime}}$, and we then proceeded to Step 1 . After paired comparison of all the schemes was accomplished, the program was terminated. On the basis of the above steps, a fuzzy complementary judgment matrix $S$ of a diversion scheme's superiority was achieved. The matrix of $S$ can be expressed as

$$
S=\left(\begin{array}{llllll}
0.5000 & 0.0000 & 0.6783 & 0.0000 & 0.0000 & 0.0000 \\
1.0000 & 0.5000 & 1.0000 & 0.0000 & 0.0000 & 0.0000 \\
0.3217 & 0.0000 & 0.5000 & 0.0000 & 0.0000 & 0.0000 \\
1.0000 & 1.0000 & 1.0000 & 0.5000 & 0.0000 & 0.0000 \\
1.0000 & 1.0000 & 1.0000 & 1.0000 & 0.5000 & 0.5490 \\
1.0000 & 1.0000 & 1.0000 & 1.0000 & 0.4510 & 0.5000
\end{array}\right)
$$

Based on Equation (20), the integrated probability that a diversion scheme is superior to the remaining five diversion schemes in the set of the six alternative diversion schemes was calculated as $h_{1}=0.1357, h_{2}=0.4000, h_{3}=0.0643, h_{4}=0.6000, h_{5}=0.9098$, and $h_{6}=0.8902$. It can be seen that, among the six diversion schemes, the probability corresponding to Scheme 5 was the maximum $\left(h_{5}\right.$ $=0.9098$ ), and the superiority ranking was obtained as $h_{5}>h_{6}>h_{4}>h_{2}>h_{1}>h_{3}$. Furthermore, the ranking reliability coefficient of the ranking result was calculated using Equations (21) and (22) as $\tau\left(h_{5}>h_{6}>h_{4}>h_{2}>h_{1}>h_{3}\right)=0.9079$. Hence, the ranking reliability of the six alternative diversion schemes of the hydropower station was quite high, and the final engineering decision can be taken with full confidence. 


\section{Conclusions}

The decision-making of the construction diversion scheme hydropower projects involves many stakeholders such as the owner unit, design unit, and construction unit and involves various factors such as investment cost, construction period, and failure risk, which belong to the category of multi-attribute group decision-making, and attribute values and weight values are often presented in the form of interval numbers due to factors such as system complexity and uncertainty. In order to solve such problems, this paper proposes a multi-attribute group decision-making method for the diversion scheme. There are three main advantages of this method: (1) By calculating the utility value and regret value of each attribute value of different schemes, the decision-maker's perceptual utility to each attribute of each scheme is obtained, so that the decision result can reflect the psychological behavior of the decision-makers, and the parameters involved are small and the calculation process is simple. (2) The decision-makers with different interest tendencies have different preferences for each attribute. The evaluation utility is indirectly determined through the method of mutual evaluation in the group, and the opinions of the decision-makers are concluded as the group opinions, which makes the evaluation process more close to the actual situation, reducing the subjectivity of each attribute weight to some degree. (3) The method uses the interval number to express the decision-maker's preference for each attribute, which is consistent with the ambiguity of the decision-making subject's thinking. The uncertainty of the preference information is described by a uniformly distributed random variable. Therefore, the overall superior ranking among the diversion schemes will be obtained in the way of probability calculation. Moreover, the results are more interpretative.

The method mentioned in this paper provides a new way to solve the multi-attribute group decision-making problem. It can be widely used in the field of decision-making process with static and single-stage multi-attribute group decision-making problem. It has a strong theoretical significance in guiding engineering decision-making problem. However, in the actual decision-making process, the selection of engineering schemes is often carried out under the condition of asymmetric decision-making information. It is the result of multi-stage game of all parties involved in the project. The dynamic and multi-stage multi-attribute group decision-making problem will be the focus among research in the future.

Author Contributions: This work was initiated, written, and put together by D.L. More technical inputs and suggestions were offered by Z.H. The language was checked by Z.H. and W.G. Critical and final reviewing of the manuscript was made by W.G.

Funding: This research was funded by National Natural Science Foundation of China grant number 51279137.

Conflicts of Interest: The authors declare no conflict of interest.

\section{References}

1. Zhang, C.; Hu, Z.G.; Liu, Q. Risk analysis for construction diversion with discharge control of the upstream hydropower stations. J. Hydraul. Eng. 2012, 11, 1328-1333.

2. Rasekh, A.; Afshar, A.; Afshar, M.H. Risk-cost optimization of hydraulic structures: Methodology and case study. Water Resour. Manag. 2010, 24, 2833-2851. [CrossRef]

3. Zhong, D.H.; Liu, D.H. Optimization based on genetic algorithms for construction diversion structures. Syst. Eng. Theory Pract. 2000, 20, 126-133.

4. Men, B.H.; Zhao, X.J.; Liang, C. Application of multi-criteria decision grey relation of projection method to hydro-engineering development plan of decision making. Eng. J. Wuhan Univ. 2003, 36, 36-39.

5. Afshar, A.; Rasekh, A.; Afshar, M.H. Risk-based optimization of large flood-diversion systems using genetic algorithms. Eng. Optim. 2009, 41, 259-273. [CrossRef]

6. Xue, J.P.; Hu, Z.G.; Liu, Q. Schemes optimization of construction diversion based on diversity of decision subject. Eng. J. Wuhan Univ. 2012, 45, 282-285.

7. Qi, X.W.; Liang, C.Y.; Zhang, E.Q. Approach to interval-valued intuitionistic fuzzy multiple attributes group decision-making problem based on maximum entropy. Syst. Eng. Theory Pract. 2011, 31, 1940-1948. 
8. Bi, W.J.; Chen, X.H. Risky mufti-criteria group decision approach based on Bayesian theory and Monte Carlo simulation. Syst. Eng. Electron. 2010, 32, 971-975.

9. Wu, G.; Gonzalez, R. Curvature of the probability weighting function. Manag. Sci. 1996, 42, 1676-1690. [CrossRef]

10. Prelec, D. The probability weighting function. Economica 1998, 66, 497-527. [CrossRef]

11. Gonzalez, R.; Wu, G. On the shape of the probability weighting function. Acad. Press 1999, 38, 129-166. [CrossRef] [PubMed]

12. Kilka, M.; Weber, M. What determines the shape of the probability weighting function under certainty? Manag. Sci. 2001, 47, 1712-1726. [CrossRef]

13. AI-Nowaihi, A.; Bradley, I.; Dhami, S. A note in the utility function prospect theory. Econ. Lett. 2008, 99, 337-339. [CrossRef]

14. Dhami, S.; AI-Nowaihi, A. Why do people pay taxes? Prospect theory versus expected utility theory. J. Econ. Behav. Organ. 2007, 64, 171-192. [CrossRef]

15. Barberis, N.; Huang, M.; Santos, T. Prospect theory and asset prices. Quart. J. Econ. 2001, 116, 1-53. [CrossRef]

16. Bell, D.E. Regret in decision making under uncertainty. Oper. Res. 1982, 30, 961-981. [CrossRef]

17. Loomes, G.; Sugden, R. Regret theory: An alternative theory of rational choice under uncertainty. The Econ. J. 1982, 92, 805-824. [CrossRef]

18. Larrick, R.P. Motivational factors in decision theories: The role of self-protectionp. Psychol. Bull. 1993, 113, 440-450. [CrossRef]

19. Ritov, I. Probability of regret: Anticipation of uncertainty resolution in choice. Organ. Behav. Hum. Decis. Processe. 1996, 66, 228-236. [CrossRef]

20. Zeelenberg, M. Anticipated regret, expected feedback and behavioral decision making. Behav. Decis. Mak. 1999, 12, 93-106. [CrossRef]

21. Coricelli, G.; Critchley, H.D.; Joffily, M.; O’Doherty, J.P.; Sirigu, A.; Dolan, R.J. Regret and its avoidance: A neuroimaging study of choice behavior. Nat. Neurosci. 2005, 8, 1255-1262. [CrossRef] [PubMed]

22. Avineri, E.; Bovy, P. Identification of parameters for prospect theory model for travel choice analysis. Transp. Res. Rec. 2008, 2082, 141-147. [CrossRef]

23. Hens, T.; Vlcek, M. Does prospect theory explain the disposition effect? J. Behav. Financ. 2011, 12, $141-157$. [CrossRef]

24. Chorus, C.G. Regret theory based route choices and traffic equilibria. Transportmetrica 2010, 8, $291-305$. [CrossRef]

25. Laciana, C.E.; Weber, E.U. Correcting expected utility for comparisons between alternative outcomes: A unified parameterization of regret and disappointment. J. Risk Uncertain. 2008, 36, 1-17. [CrossRef]

26. Zhang, X.; Fan, Z.P.; Chen, F.D. Method for risky multiple attribute decision making based on regret theory. Syst. Eng. Theory Pract. 2013, 33, 2313-2320.

27. Tversky, A.; Kahneman, D. Advances in prospect theory: Cumulative representation of uncertainty. J. Risk Uncertain. 1992, 5, 297-323. [CrossRef]

28. Bryson, N.; Mobolurin, A. An action learning evaluation procedure for multiple criteria decision making problems. Eur. J. Oper. Res. 1997, 96, 379-386. [CrossRef]

29. Lee, H.S. Optimal consensus of fuzzy opinions under group decision-making environment. Fuzzy Set. Syst. 2002, 132, 303-315. [CrossRef]

30. Madlener, R.; Antunes, C.H.; Dias, L.C. Assessing the performance of biogas plants with multi-criteria and data envelopment analysis. Eur. J. Oper. Res. 2009, 197, 1084-1094. [CrossRef]

31. Chib, S.; Greenberg, E. Markov chain Monte Carlo simulation methods in econometrics. Econom. Theory 1994, 12, 409-431. [CrossRef]

32. Zhang, F.M.; Guo, Y.J.; Yi, P.T. Method and application of group bargaining evalution based on Monte Carlo simulation. Oper. Res. Manag. Sci. 2010, 19, 63-67.

(C) 2018 by the authors. Licensee MDPI, Basel, Switzerland. This article is an open access article distributed under the terms and conditions of the Creative Commons Attribution (CC BY) license (http:/ / creativecommons.org/licenses/by/4.0/). 